\title{
Pre-implant right ventricular function might be an important predictor of the response to cardiac resynchronization therapy
}

\author{
Magnus Edner ${ }^{1 *}$, Margareta Ring ${ }^{1,2}$ and Peter Henriksson ${ }^{1}$
}

\begin{abstract}
Objective: Cardiac resynchronization therapy is proven efficacious in patients with heart failure (HF). Presence of biventricular HF is associated with a worse prognosis than having only left ventricular (LV) HF and pacing might deteriorate heart function. The aim of the study was to assess a possible significance of right ventricular (RV) preimplant systolic function to predict response to CRT.

Design: We studied $22 \mathrm{HF}$-patients aged $72 \pm 11$ years, QRS-duration $155 \pm 20$ ms and with an LV ejection fraction (EF) of $26 \pm 6 \%$ before and four weeks after receiving a CRT-device.

Results: There were no changes in LV diameters or end systolic volume (ESV) during the study. However, end diastolic volume (EDV) decreased from $226 \pm 71$ to $211 \pm 64 \mathrm{ml}(p=0.02)$ and systolic maximal velocities (SMV) increased from $2.2 \pm 0.4$ to $2.6 \pm 0.9 \mathrm{~cm} / \mathrm{s}(p=0.04)$. Pre-implant RV-SMV $(6.2 \pm 2.6 \mathrm{~cm} / \mathrm{s})$ predicted postoperative increase in LV contractility, $p=0.032$.

Conclusions: Pre-implant decreased RV systolic function might be an important way to predict a poor response to CRT implicating that other treatments should be considered. Furthermore we found that 3D- echocardiography and Tissue Doppler Imaging were feasible to detect short-term changes in LV function.
\end{abstract}

\section{Background}

Chronic heart failure (CHF) is a frequent cause of inhospital health care with a high cost. These patients have a poor quality of life (QoL) and a high readmission rate despite drugs such as RAAS- and beta-blockers, diuretics and aldosterone-antagonists which all have positive prognostic effects [1-5].

Cardiac Resynchronization Therapy (CRT) is established as an effective therapy to reduce mortality and morbidity in patients with systolic heart failure (HF) and prolonged QRS in functional class (NYHA) III-IV despite optimal medical treatment [6-10].

Dyssynchrony was pointed out as a baseline predictor of a beneficial effect of CRT in an analysis of the PROSPECT trial $[11,12]$. The analysis also pointed out other important baseline predictors of a beneficial response to CRT such as female gender, non-ischemic ethiology,

\footnotetext{
* Correspondence: magnus.edner@ki.se

'Karolinska Institutet, Division of Cardiovascular Medicine, Department of

Clinical Sciences, Danderyd Hospital, Stockholm, Sweden

Full list of author information is available at the end of the article
}

NYHA-class III, QRS-duration and no history of ventricular tachycardia. NYHA-class IV was not associated with CRT response and one reason might be that right ventricular (RV) apical pacing sometimes deteriorates LV function $[13,14]$ and many NYHA-class IV HF patients have RV dysfunction. The pathophysiologic explanations are not known for sure but could, at least partly, be that an already injured RV cannot manage the increased preload caused by better LV function in some patients. In the MADIT II trial it was found that patients receiving RV pacing had an increased prevalence of worsened heart failure than those with less RV pacing (15).

\section{Aims}

We assessed whether pre-implant systolic RV function could predict short-term response to CRT and if 3D- and TDI-echocardiography could be used to detect early changes in LV dimensions and function.

\section{C) Biomed Central}

(0) 2011 Edner et al; licensee BioMed Central Ltd. This is an Open Access article distributed under the terms of the Creative Commons Attribution License (http://creativecommons.org/licenses/by/2.0), which permits unrestricted use, distribution, and reproduction in any medium, provided the original work is properly cited. 


\section{Materials and methods Study Population}

We enrolled 22 consecutive HF patients fulfilling standard criteria for CRT. All patients had a reduced systolic left ventricular (LV) function with an ejection fraction (EF) below 35\%, QRS - duration > $120 \mathrm{~ms}$ and NYHA class III-IV despite optimal medical treatment (table 1).

Exclusion criterion was atrial fibrillation.

All patients gave informed consent. The study adhered to the Helsinki declaration and was approved by the Regional Ethical Review Board.

\section{Echocardiography and Tissue Doppler Imaging}

The patients were examined in the left lateral position and Tissue Doppler Imaging (TDI) echocardiography was acquired in three apical views using the Vivid 7 or 5 (the later for 3-D echocardiography only) systems (Vingmed, Hortem, Norway), with a $2.5 \mathrm{MHz}$ probe. Three consecutive beats were registered and mean values were used for further analysis. Analyses were made off-line (Echo-Pac software, Hortem, Norway). The 16 segments LV-model of the American Society of Echocardiography was used for orientation [16]. Base and mid LV-segments, a total of 12 , were used together with base and mid RV-segments in the 4-chamber view. The LV end diastolic dimension (LVEDd) was measured in the parasternal long axis (PLAX) view from 2D registrations. The LV end systolic diameter (LVESd) was measured in the same view with the smallest achievable LV size. Regional systolic contractility was assessed as systolic maximal velocity (SMV) during the ejection phase in the same segments. Tissue tracking (TT) was used to measure the

Table 1 Baseline characteristics $(n=22)$

\begin{tabular}{ll}
\hline Variable & HF patients \\
\hline Age (years) & $72 \pm 11(47-88)$ \\
Gender (male) & 20 \\
Heart Rate, bpm & $69 \pm 18(45-129)$ \\
QRS-width, ms & $155 \pm 20(120-190)$ \\
Function Class, NYHA (n) & \\
III & 20 \\
IV & 2 \\
Previous Myocardial Infarction & 11 \\
Hypertension & 3 \\
Dilated Cardiomyopathy & 4 \\
Diabetes & 3 \\
ACE/ARB & 22 \\
Diuretics & 22 \\
Beta-blockers & 19 \\
Spironolactone & 15 \\
\hline
\end{tabular}

Mean \pm SD unless otherwise stated. HF = heart failure, NYHA = New York Heart Association,

$\mathrm{ACEi}=$ Angiotensin Converter Enzyme Inhibitor, $\mathrm{ARB}=$ Angiotensin Receptor Blocker. longitudinal function in each segment. A mean value for $12 \mathrm{LV}$ segments was calculated to achieve a measurement of global contractility.

Trans thoracic 3D Echo was performed using a $2.5 \mathrm{MHz}$ transducer mounted in a handheld rotation device. The cardiac images were recorded from the apex during endexpiratory apnoea within one breath hold, whereby the need for respiratory triggering was abolished as previously described [17]. End diastolic volume (EDV) and End systolic volume (ESV) were measured and ejection fraction (EF) was calculated by the formula EDV-ESV/EDV $\times 100$. All examinations were performed before and four weeks after receiving the CRT-device and stored for later off-line analysis. Volumes measured by 3D echo are almost as sensitive as measured by Magnetic Resonance Imaging. Thus, we used a combination of echo methods since we believe that they are enough sensitive to detect changes during short-term follow-up.

\section{Biventricular Pacemaker Implantation}

All patients received a CRT device (Insync III ${ }^{\circledR}$, Medtronic) implanted transvenously as described previously [17].

\section{Statistical analyses}

Continuous variables with a normal distribution were analyzed by paired Students t-test and given as mean \pm SD. Other variables were analyzed by nonparametric tests and data are given as medians and range. All analyses were performed by Statistica ${ }^{\circledR}$ version 9.1 software (StatSoft, Inc., Tulsa, USA). Multivariable regression was performed by the best subset technique of Statistica. The ability of the right ventricular function variables to explain change in left ventricular function was the main analysis. The robustness of the variables to predict this change was also tested by using variable importance (VIP) in a Projection to Latent Structures (PLS)-regression analysis. We regarded $\mathrm{p}<0.05$ (two-sided) as significant.

\section{Results}

Baseline characteristics of the patients are presented in table 1. Clinical and conventional, 3D and TDI echocardiographic changes from before to four weeks after CRT implantation are shown in table 2.

There were no changes in LV diameters or ESV. However, EDV decreased from $226 \pm 71$ to $211 \pm 64 \mathrm{ml}(\mathrm{p}=$ $0.02)$ and SMV increased from $2.2 \pm 0.4$ to $2.6 \pm 0.9 \mathrm{~cm} / \mathrm{s}$ $(\mathrm{p}=0.04)$. The increase in LV-SMV could by $41 \%$ (adjusted $R^{2}$ in best subset multiple regression) be explained by pre-implant RV-SMV and RV-TT. These two variables were also shown to be the most important predictor variables in a PLS regression. Inclusion of preimplant LV-SM and LV-TT in the multivariable regression did not improve the explanation of the change in LV-SM 
Table 2 Clinical and Echocardiographic (conventional, 3D and TDI) changes from pre-implantation to four weeks after CRT implantation

\begin{tabular}{llll}
\hline Variable & $\begin{array}{l}\text { Pre- } \\
\text { implantation }\end{array}$ & $\begin{array}{l}\text { Four weeks after } \\
\text { CRT-implantation }\end{array}$ & p-value \\
\hline QRS, ms & $155 \pm 20$ & $162 \pm 29$ & n.s. \\
\hline NT-proBNP, pg/ml & $2925 \pm 2611$ & $3290 \pm 3545$ & n.s. \\
\hline Minnesota-score, median(range) & $49(11-90)$ & 0.0004 \\
\hline NYHA-class, median(range) & $3(2-4)$ & $30(1-69)$ & 0.0064 \\
\hline LV EDd, mm & $67.6 \pm 9.2$ & $2(1-3)$ & n.s. \\
\hline LV ESd, mm & $59.2 \pm 10.1$ & $67.4 \pm 8.9$ & n.s. \\
\hline MR, 0-4, median(range) & $1.5(0.5-2.5)$ & $59.3 \pm 9.9$ & 0.063 \\
\hline LV EDV, ml & $226 \pm 71$ & $1.0(0.0-2.5)$ & 0.020 \\
\hline LV ESV, ml & $169 \pm 64$ & $211 \pm 64$ & n.s. \\
\hline EF, $\%$ & $24 \pm 7$ & $163 \pm 59$ & n.s. \\
\hline Ts septum-lateral, ms & $60 \pm 31$ & $24 \pm 8$ & n.s. \\
\hline LV $T, m m$ & $3.1 \pm 1.2$ & $52 \pm 44$ & 0.038 \\
\hline LV SMV, cm/s & $2.2 \pm 0.4$ & $3.9 \pm 1.5$ & 0.045 \\
\hline RV $T, m m$ & $8.8 \pm 4.8$ & $2.6 \pm 0.9$ & n.s. \\
\hline RV SMV, cm/s & $6.2 \pm 2.6$ & $9.4 \pm 3.7$ & n.s. \\
\hline
\end{tabular}

Mean \pm SD unless otherwise stated. MR = mitral regurgitation, Ts = dyssynchrony, SMV = systolic maximal velocity, LV EDd = left ventricular end diastolic diameter, LV ESd = left ventricular end systolic diameter, EF = ejection fraction. EDV = end diastolic volume, ESV = end systolic volume, $\mathrm{TT}=\mathrm{tissue}$ tracking, RV $=$ right ventricular.

(Table 3). The significance of RV-SM persisted but RV-TT was no longer significant.

\section{Discussion}

We found that pre-implant RV systolic function as assessed by TDI could predict short-term response to CRT. The results are plausible from a mechanistic point of view but should of course be reproduced in a larger cohort of patients and with a longer follow-up.

The clinical implication of a role of pre-implant systolic $\mathrm{RV}$ function in the response to CRT should of course be that other treatments than CRT should be considered in patients with severe RV HF.

Our findings are supported by others using other methods and longer follow-up to study the importance of preimplant RV systolic function $[18,19]$. Scuteri et al used an extensive echo-Doppler examination and found that preimplant M-mode (TAPSE), RV systolic pressure measured by Doppler, RV dimensions and RV area change to be related with post-implant LV ESV remodelling [18]. They also found these relations to be consistent independent of aetiology and degree of dyssynchrony indicating the important roll of the pre-implant RV function. They suggest TAPSE $<14 \mathrm{~mm}$, a simple and highly reproducible method, as cut-off value to define advanced RV dysfunction and found this cut-off to be associated with a twofold risk of the combined end point of death and emergency heart transplantation. In another study by Tabereaux et al a visual grading by 2D echocardiography of the RV function was used [19]. RV EF < 40\% was the definition of RV systolic dysfunction and found to be associated to less response to CRT during 6 month's follow-up. Thus, the importance of preserved pre-implant systolic RV function has been demonstrated by different methods in HF patients with standard indication for CRT.

A suggested echocardiographic cut-off value of response to CRT is an decrease by approximately $10 \%$ in the end

Table 3 Results of multivariable regression of the influence of pre-implant RV-SM, RV-TT, LV-SM and LV-TT on change in LV-SM four weeks after CRT implantation

\begin{tabular}{llllc}
\hline & Parameter & $\mathbf{9 5 . 0 0 \%}$ Confidence interval & p-value & Beta-value \\
\hline Intercept & 0.067 & $(-1.74-1.87)$ & 0.94 & 0.032 \\
\hline RV SM & 0.25 & $(0.024-0.47)$ & 0.15 & -0.59 \\
\hline RV TT & -0.13 & $(-0.31-0.05)$ & 0.77 & -0.10 \\
\hline LV SMV & -0.18 & $(-1.46-1.10)$ & 0.97 & -0.014 \\
\hline LV TT & -0.01 & $(-0.53-0.51)$ & & \\
\hline
\end{tabular}

$\mathrm{RV}=$ right ventricular, $\mathrm{LV}=$ left ventricular, $\mathrm{SMV}=$ systolic maximal velocity, $\mathrm{T}=$ tissue tracking. 
diastolic and end systolic volume [20,21]. However, this is after 12 weeks CRT and there are no certain parameters to be measured to define a response already after four weeks of CRT. Thus, in this study we chose a combination of clinical parameters such as patient-assessed functional class and quality of life and echocardiographic parameters such as LV diameters (conventional echo), LV volumes (3D echo) and myocardial velocities and longitudinal movement (TDI) to decide whether there where a response after four weeks of CRT or not. According to this approach $68 \%$ of the patients responded to CRT in this study, which main aim however was to assess the importance of the pre-implant systolic RV function. 3D echo has been reported almost as sensitive as magnetic resonance imaging when measuring LV volumes and Müller-Brunotte at al reported TDI to be more sensitive than conventional echo measuring effects after treatment of hypertension induced LV hypertrophy [22]. It seems obvious that echocardiography should be used more when planning or doing follow-up in CRT since a lot of important information is given. However, the technique requires time and special interest and if it has to be done in all patients it might result in underuse of the CRT, a very effective treatment which probably is underused already today.

One explanation to the suggested importance of preimplant systolic RV function might be a preload increase caused either by an acute deterioration in RV systolic function or by a miss match improvement where the LV function improves more than the RV function resulting in non-responding to CRT.

Furthermore, in the revised ESC guidelines on device therapy in HF it is pointed out that conventional pacing might increase symptoms and deteriorate LV function and therefore biventricular pacing is recommended regardless of QRS prolongation in patients with LV dysfunction and signs of HF [23].

In conclusion our findings implicate that pre-implant RV systolic function might be an important predictor of the poor response to CRT in some patients with biventricular heart failure and other treatments should be considered in these patients. Furthermore 3D- echocardiography and TDI seem feasible to detect changes in LV function during short-term follow-up.

\section{Disclosures}

No conflicts of interest.

\section{Acknowledgements}

We thank Jenny Rasck for skilful technical assistance.

Funding

This study was supported with grants from the Karolinska Institutet and Medtronic.

\section{Author details}

'Karolinska Institutet, Division of Cardiovascular Medicine, Department of Clinical Sciences, Danderyd Hospital, Stockholm, Sweden. ${ }^{2}$ Department of Molecular Medicine and Surgery, Karolinska Institutet, Stockholm, Sweden.

\section{Authors' contributions}

ME was responsible for planning and writing. MR and PH performed echocardiographic and statistical analyses and helped writing manuscript. All authors read and approved the final manuscript.

Received: 6 June 2011 Accepted: 26 October 2011

Published: 26 October 2011

\section{References}

1. Mostered A, Hoes AW, de Bruyne MC, Deckers JW, Linkerr DT, Hofman A, et al: Prevalence of heart failure and left ventricular dysfunction in the general population. The Rotterdam study. Eur Heart J 1999, 20:447-55.

2. Mejhert M, Persson H, Edner M, Kahan T: Epidemiology of heart failure in Sweden - a national survey. Eur J Heart Fail 2001, 3:97-103.

3. Stewart S, MacIntyre K, MacLeod MMC, Bailey AEM, Capewelm S, MacMurray JJV: Trends in hospitalisation for heart failure in Scotland, 1990-1996. Eur Heart J 2001, 22:209-17.

4. Cleland JGF, Gemmell I, Khand A, Boddy A: Is the prognosis of heart failure improving? Eur J Heart Fail 1999, 1:229-41.

5. The Task Force: ESC guidelines for the diagnosis and treatment of acute and chronic heart failure 2008. Eur Heart J 2008, 29:2388-2442.

6. Penika M, Bartunek J, De Bruyne B, Vanderheyden M, Goethals M, De Zutter $M$, et al: Improvement of left ventricular function after cardiac resynchronization therapy is predicted by tissue Doppler imaging echocardiography. Circ 2004, 109:978-83.

7. St John Sutton MG, Plappert T, Abraham WT, Smith AL, DeLurgio DB, Leon AR, et al: Effect of cardiac resynchronization therapy on left ventricular size and function in chronic heart failure. Circ 2003, 107:1985-90.

8. Abraham WT, Fisher WG, Smith AL, for the MIRACLE Study Group: Multicenter insync randomized clinical evaluation. Cardiac resynchronization in chronic heart failure. N Engl J Med 2002, 346:1845-53.

9. Bristow MR, Saxon LA, Boehmer J, Krueger S, Kass DA, De Marco T, et al: Cardiac resynchronization therapy with and without an implantable defibrillator in advanced chronic heart failure. N Engl J Med 2004 350:2140-50

10. Cleland JGF, Daubert JC, Erdman E, Freemantle N, Gras D, Kappenberger L, et al: The effect of cardiac resynchronization on morbidity and mortality in heart failure. New Eng J Med 2005, 352:1539-49.

11. Chung ES, Leon AR, Tavazzi L, Sun JP, Nihoyannopoulos P, Merlino J, Abraham WT, Ghio S, Leclercq C, Bax JJ, Yu CM, Gorscan J III, St John SM, De Sutter J, Murillio J: Results of the predictors of response to CRT (PROSPECT) trial. Circ 2008, 117:2608-16.

12. van Bommel RJ, Bax JJ, Abraham WT, Chung ES, Pires LA, Tavazzi L, Zimetbaum PJ, Gerritse B, Kristiansen N, Ghio S: Characteristics of heart failure patients associated with good and poor response to cardiac resynchronization therapy: a PROSPECT (predictors of response to CRT) sub-analysis. Euro Heart J 2009, 30:2470-77.

13. Tse H-F, Lau C-P: Long-term effect of right ventricular pacing on myocardial perfusion and function. J Am Coll Cardiol 1997, 29:744-9.

14. Tse H-F, Yu C, Wong K-K, Tsang V, Leung Y-L, Ho W-Y, Lau C-P: Functional abnormalities in patients with permanent right ventricular pacing. J Am Coll Cardiol 2002, 40:1451-8.

15. Steinberg JS, Fischer A, Wang P, Schuger C, Daubert J, Mcnitt S, Andrews M, Brown M, Hall JW, Zareba W, Moss A: The clinical implications of cumulative right ventricular pacing in the multicenter automatic defibrillator trial II. J Cardiovasc Electrophysiol 2005, 16:359-65.

16. American Society of Echocardiography Committee on standards, Subcommittee on Quantitation of Two-Dimensional Echocardiograms, Schiller NB, Shah PM, DeMaria A, Devereux R, Feigenbaum $H$, et al: Recommendations for quantitation of the left ventricle by twoDimensional Echocardiography. J Am Soc Echocardiogr 1989, 2:358-67.

17. Edner M, Ring M, Sarev T: Sequential biventricular pacing improves regional contractility, longitudinal function and dyssynchrony in patients with heart failure and prolonged QRS. Cardiovascular Ultrasound 2010, 8:12. 
18. Scuteri L, Rordorf R, Marsan NA, Landolina M, Magrini G, Klersy C, Frattini F, Petracci B, Vicentini A, Campana C, Tavazzi L, Ghio S: Relevance of echocardiographic evaluation of right ventricular function in patients undergoing cardiac resynchronization therapy. PACE 2009, 32:1040-9.

19. Tabereaux PB, Doppalapudi H, Kay GN, Mcelderry T, Plumb VJ, Epstein AE: Limited response to cardiac resynchronization therapy in patients with concomitant right ventricular dysfunction. J Cardiovasc Electrophysiol 2009, 19:1-5.

20. Yu CM, Chau E, Sanderson JE, et al: Tissue Doppler echocardiographic evidence of reverse remodeling and improved synchronicity by simultaneously delaying regional contraction after biventricular pacing therapy in heart failure. Circulation 2002, 105:438-45.

21. Saxon LA, De marco T, Shafer J, et al: Effects of long-term biventricular stimulation for resynchronization on echocardiographic measures of remodeling. Circulation 2002, 105:1304-10.

22. Muller-Brunotte R, Kahan T, Malmqvist K, Edner M: Tissue Doppler Imaging shows early improvement in diastolic function by irbesartan and atenolol in patients with hypertensive left ventricular hypertrophy. Am J Hypertension 2006, 16:927-36.

23. The Task Force: 2010 Focused update of ESC guidelines on device therapy in heart failure. Euro Heart J 2010, 31:2677-87.

doi:10.1186/1476-7120-9-28

Cite this article as: Edner et al:: Pre-implant right ventricular function might be an important predictor of the response to cardiac

resynchronization therapy. Cardiovascular Ultrasound 2011 9:28.

\section{Submit your next manuscript to BioMed Central} and take full advantage of:

- Convenient online submission

- Thorough peer review

- No space constraints or color figure charges

- Immediate publication on acceptance

- Inclusion in PubMed, CAS, Scopus and Google Scholar

- Research which is freely available for redistribution

Submit your manuscript at www.biomedcentral.com/submit
C Biomed Central 